\title{
ATELLE \\ A aula como resistência ao autoritarismo: pensar um campo de luta na sala de aula e para além dela
}

\author{
The class seen as resistance to authoritarianism: thinking of \\ a battle field in the classroom and beyond
}

\section{La clase en contra del autoritarismo: pensar un campo de lucha en el aula y más allá de ella}

\author{
Bruno Andrade Ribeiro \\ Universidade Federal de Sergipe (UFS) \\ ribeiro.pensador@gmail.com \\ Josefa de Lisboa Santos \\ Universidade Federal de Sergipe (UFS) \\ josefalisufs@gmail.com
}

\begin{abstract}
Resumo
Em tempos nos quais saudar torturadores tornou-se exercício comum a candidatos eleitos na democracia procedimental brasileira, negar o pensamento crítico como manutenção de discursos e práticas autoritárias se configura em projeto para uma nação desmemoriada. O espaço que se pensa pela e para a classe dominante é aquele que explore de modo eficiente a força de trabalho em um constante estado de exceção, que contrapõe o bem-estar e a criatividade humana, em prol do crescimento econômico, sempre pífio no contexto de crise estrutural do capital. Nesse sentido, o presente artigo argumenta sobre a importância das aulas de Geografia na contraposição ao autoritarismo e destituição do pensamento crítico, representados pelo combate ao marxismo, fortalecimento do agronegócio e negação dos direitos trabalhistas. Portanto, parte-se da compreensão de que a crítica do discurso geográfico envolve a compreensão de que não se formula uma teoria a partir da descrição da realidade imediata, mas através da transformação histórica do real, em uma contínua relação entre prática e reflexão.
\end{abstract}

Palavras-chave: Trabalho, Espaço, Pensamento Crítico, Aulas de Geografia.

\footnotetext{
Abstract

In times when greeting torturers became a common exercise for candidates elected in Brazilian procedural democracy, denying critical thinking as maintenance of
} 
discourses and authoritarian practices is configured in a project for a nation deprived of memory. The space that is thought by and for the ruling class is one that efficiently exploits the workforce in a constant state of exception, which opposes human well-being and creativity in favor of economic growth, always insignificant in the context of structural crisis of capital. In that regard, this article argues about the importance of geography classes in opposition to authoritarianism and the dismissal of critical thinking represented by the combat to Marxism, the strengthening of agribusiness and denial of workers' rights. Thus, it starts from the understanding that the critique of the geographical discourse involves the understanding that a theory is not formulated from the description of the immediate reality, but through the historical transformation of the real, in a continuous relationship between practice and reflection.

Keywords: Work, Space, Critical thinking, Geography classes.

\begin{abstract}
Resumen
En tiempos en que saludar los torturadores se convirtió en ejercicio común a candidatos elegidos en la democracia procedimental brasileña, negar el pensamiento crítico como mantenimiento de discursos y prácticas autoritarias configurase en proyecto para una nación olvidadiza. El espacio que se piensa por y para la clase dominante es aquel que explota de modo eficiente la fuerza de trabajo en un constante estado de excepción, que contrapone el bienestar y la creatividad humana, en favor del crecimiento económico, siempre pequeño en el contexto de crisis estructural del capital. En este sentido, el presente artículo argumenta sobre la importancia de las clases de Geografía en la contraposición al autoritarismo y destitución del pensamiento crítico, representados por enfrentamiento al marxismo, fortalecimiento del agronegocio y negación de los derechos laborales. Por lo tanto, se parte de la comprensión de que la crítica del discurso geográfico implica la comprensión de que no se formula una teoría a partir de la descripción de la realidad inmediata, sino a través del cambio histórico del real, en una continua relación entre práctica y reflexión.
\end{abstract}

Palabras-clave: Trabajo, Espacio, Pensamiento crítico, Clases de Geografía

\title{
Introdução: como evitar a cegueira generalizada?
}

O alvorecer de 2019 exige a teoria crítica e a crítica da teoria para que se possa chegar aos campos de enfrentamento contra o projeto de negação dos camponeses, povos indígenas, quilombolas e trabalhadores urbanos. A cegueira reproduzida cotidianamente pelos principais veículos midiáticos para mais de 200 milhões de brasileiros é proposital para que o desmonte ultraliberal seja efetivado e considerado como 'reforma' necessária para a volta do crescimento econômico.

Nesse contexto, a realidade começa a ganhar contornos de uma distopia como a que Ray Bradbury imaginou em Fahrenheit 451: livros são proibidos e devem ser queimados a uma temperatura suficiente para transformá-los em cinzas e as pessoas devem ser 'enchidas' de dados incombustíveis, entupidas de fatos para sentirem-se brilhantes e imaginando que estão pensando: “[...] e ficarão felizes, porque fatos dessa 
ordem não mudam. Não as coloque em terreno movediço, como Filosofia ou Sociologia, com que comparar suas experiências" (BRADBURY, 2012, p. 84).

Desse modo, o artigo propõe o debate sobre a atualidade da questão agrária e trabalhista no Brasil, pensando um campo de luta a partir da aula de Geografia, dentro e fora da sala, escola e universidade. A princípio, como questionamento da tragédia neoliberal em sua negação ao pensamento crítico, enfatizada no plano de (des)governo do presidente eleito como combate às 'ideologias de esquerda', 'marxismo', 'comunismo' e 'socialismo', desconstrói-se o discurso de "Brasil acima de tudo, Deus acima de todos" como instrumento ideológico de ocultação dos planos de entrega dos recursos naturais, de exploração da renda da terra e destituição dos povos indígenas e quilombolas como objetivo do agronegócio e da bancada ruralista que o sustenta na Câmara dos Deputados e no Senado Federal. O suposto fim do pensamento crítico, descrito pela classe burguesa como dogma e doutrina, exige que o país retorne o objetivo positivista de levar ordem e progresso aos seus habitantes; sem ao menos compreender Auguste Comte e o contexto de emergência de suas ideias e seu método. A moral e os valores da sociedade tradicional brasileira se sobrepõem à desigualdade estrutural que sustenta a acumulação e o lucro de alguns poucos privilegiados da injusta nação de parca experiência democrática.

$\mathrm{Na}$ busca da neutralidade e do fim da criticidade, tudo aquilo que questionar a ordem natural das coisas deve ser descartado, pois expor as contradições intrínsecas à realidade significa contrapor a moral e os bons costumes que embasam a aparência da sociedade burguesa e encobrem seu real caráter destrutivo. Desse modo, ressalta-se a importância das aulas de Geografia na contraposição ao autoritarismo e a tentativa de destituição do pensamento crítico. Aqui, tem-se como ponto de partida as aulas da disciplina Estrutura Agrária, ofertada no âmbito do Programa de Pós-Graduação em Geografia da Universidade Federal de Sergipe (PPPGEO/UFS), no segundo semestre de 2018, na qual conteúdos, debates e o trato com a realidade congregaram para a devida negação da fixidez e de toda a reificação imposta pelo mundo da mercadoria.

\section{A tragédia neoliberal como negação do pensamento crítico: desconstruir o que existe por trás do "Brasil acima de tudo, deus acima de todos"}

O discurso ufanista e moralista, baseado na defesa dos 'homens de bem', que avança no Brasil do final dessa década esconde o que existe de mais promíscuo e

\footnotetext{
${ }^{1}$ Como no poema de Bertolt Brecht, a realidade exige um constante interrogatório para a desconstrução dos "homens de bens": "Chega mais: Nós ouvimos que você é um homem de bem. Você não é comprável, mas o raio que cai em cima da casa, também não é comprável. O que você diz uma vez, você mantém. O que você disse? Você é honesto, você diz sua opinião. Que opinião? Você é corajoso. Contra quem? Você é sábio. Para quem? Você não quer tirar vantagem. Vantagem de quem? Você é um bom amigo. De gente de bem também? Então ouça: Nós sabemos, você é nosso inimigo. Por isso queremos o colocar agora no paredão. Mas em consideração a seus méritos. E boas qualidades. Num bom paredão e o fuzilar com boas balas de bons fuzis e $o$ enterrar com uma boa pá em boa terra”.
} 
antipatriótico na nova agenda política: a burguesia brasileira necessita entregar-se ao neoliberalismo, que desde a descoberta do pré-sal atrai a ganância sem limites do governo estadunidense. E enquanto a classe média acredita que se tornará elite após vestir verde e amarelo nas avenidas das principais cidades brasileiras, batendo panelas nas janelas de seus apartamentos contra a 'esquerda comunista', a elite se articula à extrema-direita para a destituição do Estado desenvolvimentista e a perpetuação de propostas ultraneoliberais. $\mathrm{O}$ espaço que se pensa nas medidas encabeçadas por Paulo Guedes - um dos Chicago Boys - é o espaço para que a classe dominante possa acumular capital de forma eficiente, travestido pelo discurso de enxugamento da máquina pública, que exige cortes drásticos nas áreas de educação, saúde, previdência social, assistência social, meio ambiente, esportes e direitos trabalhistas ${ }^{2}$ (FIGURA 1).

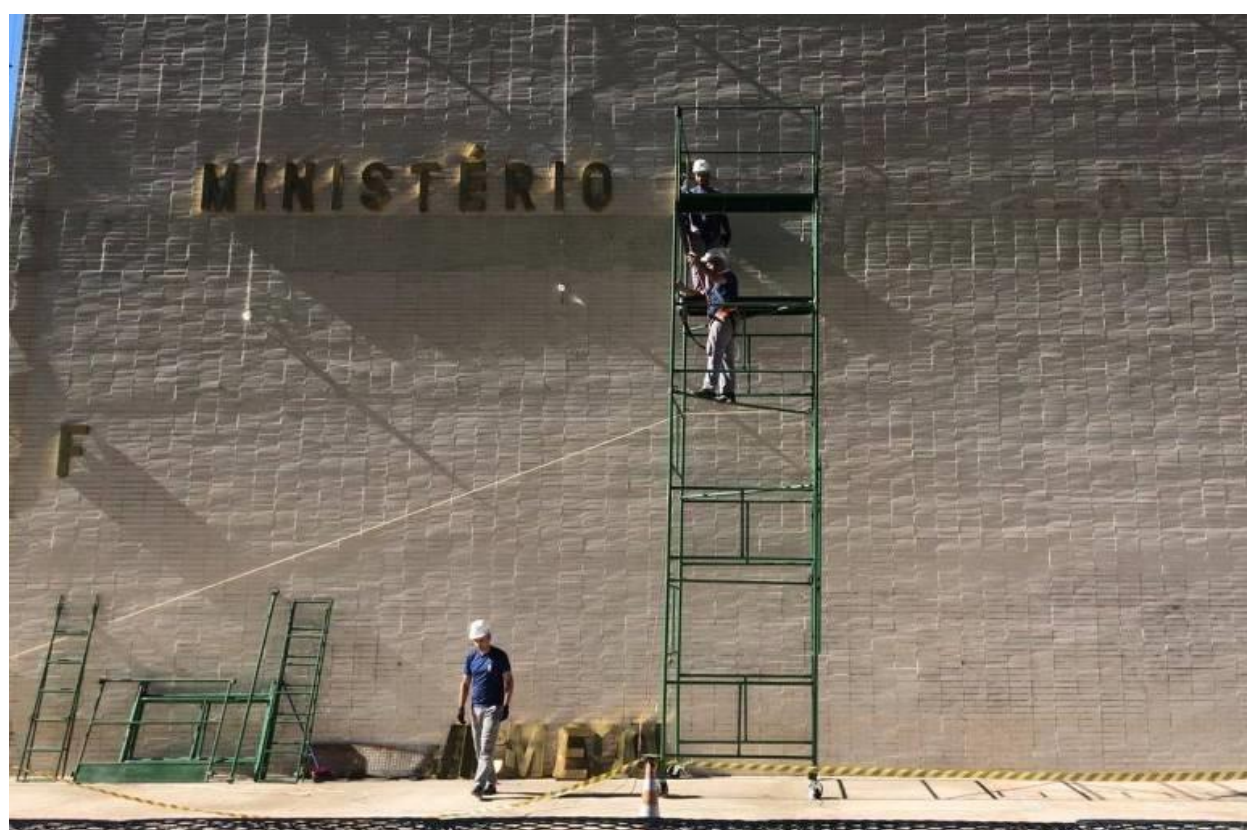

Figura 1: Trabalhadores retiram letreiro do extinto Ministério do Trabalho e Emprego, janeiro de $2019^{3}$

Fonte: Folha de São Paulo (2019)

No âmbito da tragédia neoliberal, a Geografia, que desde o impeachment da Presidenta da República Dilma Rousseff vem sendo ameaçada enquanto ciência, deve se tornar mera disciplina optativa, e quando presente, reduzindo-se ao que se propunha nas

2 Disponível em: https://www.cartacapital.com.br/politica/cinco-medidas-em-que-o-governo-bolsonaro-jamostra-a-que-veio/. Acesso: 04 jan. 2019.

3 Disponível: https://www1.folha.uol.com.br/poder/2019/01/novo-governo-retira-letreiro-do-ministerio-dotrabalho-agora-extinto.shtml. Acesso: 04 jan. 2019. 
cátedras dos governos ditatoriais: memorizações, ode ao nacionalismo falacioso, aos símbolos oficiais e ao Brasil da ordem e do progresso, pronto para ser reinserido no Mapa da Fome, na lista de maiores poluidores globais e continuando a ser o país que mais mata camponeses, LGBTQ+, negros e mulheres. Para tal, o (des)governo bolsonarista estabelece como diretrizes iniciais, o banimento do debate sobre gênero, condição sexual, cor, raça e credo (transmutados em "ideologias de gênero") e sobre desigualdade social, pois o marxismo deve ser excluído das escolas e universidades, para que se garanta a formação de homens-lata ${ }^{4}$. O novo Ministro da Educação, por exemplo, afirmou que "não permitirá assuntos que vão contra os costumes familiares 5 "; enquanto a Ministra da Mulher, Família e Direitos Humanos disse que nessa 'nova era', "menino veste azul e menina veste rosa", E é nesse sentido que se faz necessário desconstruir o discurso de "Brasil acima de tudo, Deus acima de todos".

Ao argumentar sobre a situação dos trabalhadores pobres nas vésperas da Revolução de 1848, Eric Hobsbawm escreve:

A introdução de um sistema individualista puramente utilitário de comportamento social, a selvagem anarquia da sociedade burguesa, teoricamente justificada por seu lema "cada um por si e Deus por todos" parecia aos homens criados nas sociedades tradicionais pouco melhor do que a maldade desenfreada (HOBSBAWM, 2010, p. 368).

O historiador egípcio ${ }^{7}$, desse modo, descortina a desumanidade atrelada à sociedade burguesa, cuja riqueza dependia da miséria de massas cada vez maiores de trabalhadores, que acreditavam na realidade desigual como fruto da ordem natural de Deus. Porém, cada vez mais sujeitos a condições deploráveis, com epidemias dizimando a população camponesa, operária e doméstica, sem acesso à água, sistema sanitário e comida, a alternativa foi a rebelião; não como simples protesto temporário, mas, em seu movimento contínuo, como construção de um novo modo de produção contra o capitalismo.

No Brasil pós-2018, em que massas de desempregados aumentam a cada mês, conforme as pesquisas contínuas do Instituto Brasileiro de Geografia e Estatística (IBGE), valendo-se da informalidade como possibilidade de manter as condições materiais de existência o discurso religioso como defesa da moral e da ordem é inculcado na mentalidade nacional como única possibilidade de transformar a nação

\footnotetext{
4 "Educa-se para ser individualista; para cultivar o particular, a autoconservação. Para resolver a própria vida, ou para se ter noção de um 'eu' que não se vê como parte de um todo".

5 Disponível em: https://www.terra.com.br/noticias/educacao/novo-ministro-da-educacao-promete-priorizarensino-basico-e-combater-marxismo-nas-escolas,49f6580ae7ea97fa7345af773a92267czfwzwjb5.html. Acesso em: 02 jan. 2019.

6 Disponível em: https://www1.folha.uol.com.br/poder/2019/01/menino-veste-azul-e-menina-veste-rosa-dizdamares.shtml. Acesso em: 04 jan. 2019.

${ }^{7}$ Eric Hobsbawm é considerado, na maioria dos estudos, como britânico, devido ao domínio deste Império sobre o Egito.
} 
'corrompida pelo petismo comunista' em uma pátria livre de 'ideologias de esquerda', marxismo e socialismo. De acordo com os dados do IBGE para agosto de 2018, faltavam trabalho para 27,6 milhões de brasileiros; os subutilizados (desempregados, trabalhadores com carga horária inferior a 40 horas semanais, os que desistiram de procurar emprego) formavam $24,7 \%$ de toda a População Economicamente Ativa (PEA) do país. No gráfico abaixo (FIGURA 2), por exemplo, pode-se observar o aumento de brasileiros subutilizados nos últimos anos, saltando de 15,3 milhões no $2^{\circ}$ trimestre de 2014 para 27,7 milhões no $1^{\circ}$ trimestre de 2018.

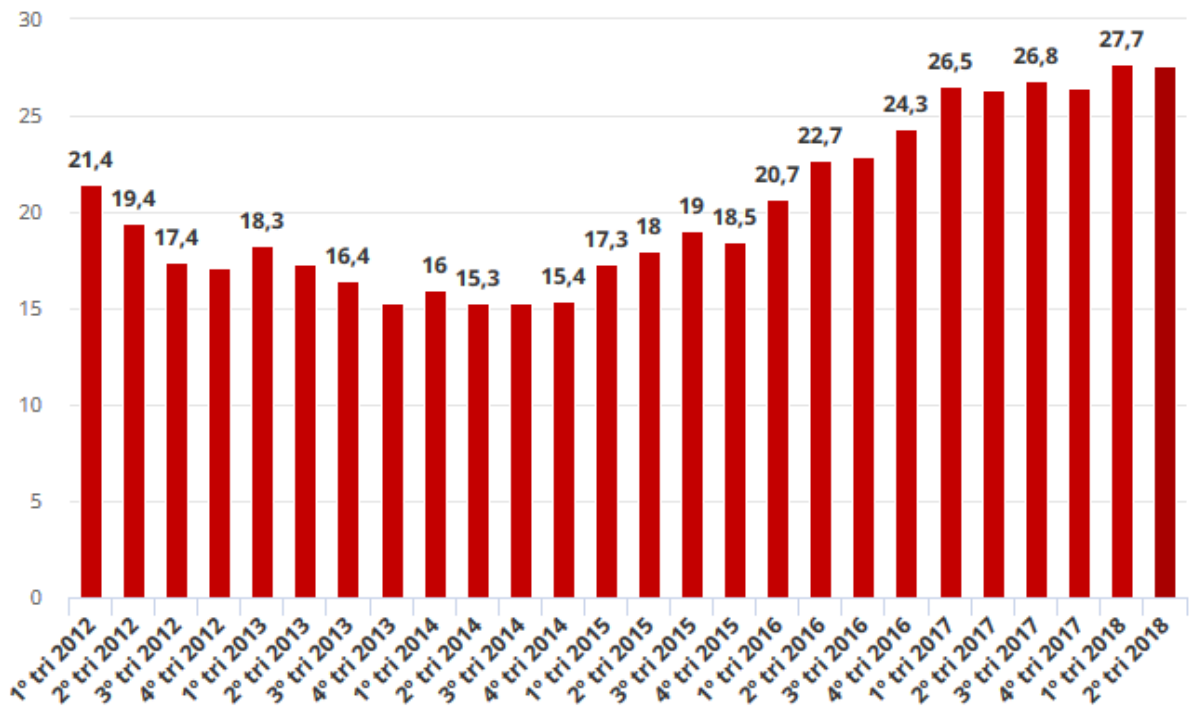

Figura 2: Número de força de trabalho subutilizada no Brasil, em milhões (2012-2018) Fonte: PNAD Contínua

Nessa discussão, o combate ao pensamento crítico em um contexto global de crises econômicas devastadoras se insere como projeto reacionário de uma elite que não enxerga como positiva as conquistas sociais dos últimos 10 anos, vistas como esmolas que mantiveram maus costumes da 'ralé' brasileira. No presente escrito, concorda-se com Eagleton (2012), quando este afirma que as ideias marxistas não são perfeitas, mas plausíveis, pois é inegável que tenha transformado a compreensão da história humana. Desse modo, quando se escreve sobre o capitalismo parte-se do princípio de que o sistema deixou de ser natural, sendo compreendido como fenômeno histórico recente e que não será eterno.

De acordo com Eagleton (2012), uma das críticas ao marxismo diz respeito à relevância restrita a um mundo de fábricas e escassez de comida da Inglaterra do século XIX, pois o mundo está cada vez menos classista e 'melhor' para se viver. Todavia, esquece-se que o marxismo é uma crítica ao capitalismo - a mais investigativa, rigorosa 
e abrangente -, e enquanto este existir como modo de produção, o marxismo precisará fazer o mesmo, enquanto concepção teórico-filosófica. O próprio Marx tinha consciência da natureza mutante do sistema, oferecendo uma compreensão sobre as diferentes formas históricas de capital; portanto, o questionamento a ser feito é: "Por que desqualificar uma teoria que encara a mudança como a própria essência do sistema? " (EAGLETON, 2012, p. 14). Através das contribuições do materialismo histórico e dialético entende-se que a desigualdade cresceu de forma dramática nas últimas décadas e, a partir dela, o capitalismo criou a prosperidade como nunca antes, testemunhando a penúria de bilhões de seres no mundo, pois “[...] é incapaz de inventar um futuro que não reproduza seu presente ritualmente" (EAGLETON, 2012, p. 17).

Nesse sentido, o mito do neoliberalismo traz consigo um individualismo possessivo, no qual parcelas amplas de seres humanos perdem a possibilidade de vender a única posse: sua força de trabalho. "A assim chamada acumulação primitiva" de que nos escreve Marx deve ser compreendida como contínuo processo de separação do ser humano de seus meios de produção. A relação capitalista pressupõe a separação entre trabalhadores e a propriedade das condições da realização do trabalho. $\mathrm{O}$ produtor necessitou deixar de ser servo, acorrentado à gleba, para se tornar livre vendedor de sua força humana. Contudo, só se converteram em vendedores de si mesmos quando todos os meios de produção e todas as garantias de sua existência foram furtados (MARX, 2017). O modelo flexível de acumulação que emerge, a princípio, no Chile do sanguinário Pinochet, sob orientação dos Chicago Boys, se constitui em fase do capitalismo maduro, no qual necessita se apresentar duro, livre de regras e valendo-se da desigualdade social e da penúria de bilhões de seres humanos como valor positivo para a perpetuação de mais-valor. Além disso, nas ditaduras e democracias frágeis, o neoliberalismo parece ganhar ainda mais eficácia, através de cortes sociais sob o título de 'reformas'. No "Brasil acima de tudo, Deus acima de todos", desse modo, a única coisa que interessa é a acumulação: lucro acima de tudo, dinheiro acima de todos.

O combate ao marxismo, estigmatizado nos corredores de algumas pósgraduações como 'pensamento hegemônico', 'dogma' ou 'pensamento único' se justifica pela fragmentação do pensamento, na negação das categorias universais e crença de que o discurso do 'um' será capaz de frear o sistema sociometabólico do capital. E nessa cegueira generalizada, muitos que defendem a esquerda brasileira contra o avanço do bolsonarismo, fortalecem em suas práticas acadêmicas a negação do pensamento crítico e a defesa de uma Geografia sem Marx. Portanto, unem-se ao projeto - esse sim, verdadeiramente hegemônico e autoritário -, de formar seres-lata, supérfluos e descartáveis. 


\section{"Nem um centímetro a mais para terras indígenas"}

Se a acumulação de capital é uma condição atemporal para os mecanismos de perpetuação do modo de produção capitalista, a conversão da terra em valor de troca e a valorização de valor através de formas de exploração de trabalho camponês estão intrínsecas ao modelo de agronegócio que se sustenta no Brasil. Nesse contexto, o governo Bolsonaro se insere como determinante para a perpetuação da estrutura fundiária concentrada e a consolidação do projeto ruralista, mantendo o que existe de mais arcaico para a lavoura brasileira: trabalho similar ao escravo, negação do acesso à terra aos camponeses, quilombolas e povos indígenas, facilitação da entrada de venenos altamente tóxicos à saúde humana e expansão da fronteira agrícola para a plantação de soja.

Em 2017, o número homicídios e massacres no campo foi de 71 pessoas assassinadas - maior índice desde 2003, de acordo com o Caderno Conflitos no Campo Brasil 2017, produzido pela Comissão Pastoral da Terra (CPT). Sobre ocorrências de trabalho escravo no ano de 2017, a CPT documentou 530 denúncias em 66 municípios brasileiros; a maioria das ocorrências em grandes fazendas e garimpos. Além disso, desde 1988 não ocorrera dois massacres em um único ano (Colniza, no Mato Grosso e Pau D'Arco, no Pará). No quadro abaixo (QUADRO 1), pode-se observar alguns dados complementares, que corroboram para a compreensão sobre o estado de exceção que o campo brasileiro perpassa:

Quadro 1: Dados de ocorrências sobre violência no campo brasileiro, 2017

\begin{tabular}{|c|c|}
\hline Tipo de ocorrência & Total \\
\hline Tentativas de homicídios & 120 \\
\hline Ameaças de morte & 226 \\
\hline Famílias despejadas & 10.622 \\
\hline Famílias expulsas & 1.448 \\
\hline Ameaças de expulsão & 24.577 \\
\hline Casas destruídas & 4.573 \\
\hline Famílias sob ameaça de pistoleiros & 16.800 \\
\hline
\end{tabular}

Fonte: Caderno Conflitos no Campo Brasil 2017 (CPT)

Com relação à entrada de venenos agrícolas, o Art. $3^{\circ}$ da Lei 7.802, de 11 de julho de 1989 determina que: "Os agrotóxicos, seus componentes e afins, de acordo com definição do art. $2^{\circ}$ desta Lei, só poderão ser produzidos, exportados, importados, comercializados e utilizados, se previamente registrados em órgão federal, de acordo com as diretrizes e exigências dos órgãos federais responsáveis pelos setores da saúde, do meio ambiente e da agricultura". Em 2018, porém, a aprovação do Relatório do Deputado Luiz Nishimori (PR-Paraná), o Projeto de Lei 6299/02, com apoio da Bancada Ruralista, tende a flexibilizar tais regras, facilitando a entrada de substâncias proibidas

${ }^{8}$ Disponível em: https://deolhonosruralistas.com.br/2018/02/08/nem-um-centimetro-mais-para-terras-indigenas-dizbolsonaro/. Acesso em: 04 jan. 2019. 
até o momento, trocando a palavra 'agrotóxico' por 'pesticida' e ocultando os riscos cancerígenos e de má formação congênita atrelados aos venenos agrícolas, como informa o Instituto Nacional do Câncer (INCA). Desse modo, o Ministério da Agricultura coloca-se contra as recomendações do Instituto Brasileiro de Meio Ambiente (IBAMA), Ministério da Saúde, Fundação Oswaldo Cruz (Fiocruz) e Agência Nacional de Vigilância Sanitária (ANVISA). A votação sobre a aprovação definitiva da "PL do Veneno" na Câmara dos Deputados tem previsão para 2019, e com a vitória de Jair Bolsonaro, o que esperar?

No posto de Ministra da Agricultura está a 'musa do veneno', Tereza Cristina Corrêa da Costa Dias, líder da Frente Parlamentar Agropecuária (FPA), e, após mudanças na estrutura ministerial, responsável pela demarcação de terras indígenas e quilombolas, com o enfraquecimento da Fundação Nacional do Índio (FUNAI).

De acordo com a página eletrônica oficial da FPA, o objetivo é "estimular a ampliação de políticas públicas para o desenvolvimento do agronegócio nacional. Dentre as prioridades atuais estão a modernização da legislação trabalhista, fundiária e tributária, além da regulamentação da questão de terras indígenas e áreas quilombolas, a fim de garantir a segurança jurídica necessária à competitividade do setor”. A 'modernização' que interessa à Bancada assassina que a nova Ministra lidera, significa o fim de 232 processos em curso de demarcações de terra indígena ${ }^{9}$ e a continuação de massacres no campo, como o que vitimou Rodrigo Celestino e José Bernardo da Silva, no Acampamento Dom José Maria Pires, na Paraíba, em dezembro de $2018^{10}$. Desse modo, notícias ocultadas pela grande mídia poderão se multiplicar a partir de 2019, como algumas que se encontram no Jornal El País: "Escola e posto de saúde de comunidade indígena são incendiados em área de conflito com ruralistas ${ }^{11 " ; ~ " B e b e ̂ ~}$ morto com tiro na cabeça é um cruel símbolo da situação dos povos indígenas no Brasil $^{12 " ; ~ " M o r t e ~ d e ~ c a c i q u e ~ n o ~ M a r a n h a ̃ o ~ e ́ ~ n o v o ~ c a p i ́ t u l o ~ d e ~ i n v a s o ̃ e s ~ n a ~ r e g i a ̃ o, ~}$ segundo indígenas ${ }^{13}$ ".

Em seu percurso histórico, o agronegócio emerge travestido de "Revolução Verde" e de diversificação das pautas de exportação, com o Estado mediando a realização de mais-valor através da formação de estoques de mercadorias para baixar os preços das novas commodities. O território brasileiro deveria se integrar e modernizar através da ampliação da fronteira agrícola e a introdução de técnicas avançadas de plantio e colheita, sem qualquer preocupação com o desmatamento, a contaminação de aquíferos e cursos fluviais e a expulsão de povos que habitavam terras desde antes da

\footnotetext{
${ }^{9}$ Disponível em: https://deolhonosruralistas.com.br/2019/01/03/230-territorios-de-quilombolas-tem-reconhecimentoameacado-pelo-governo-cunhado-de-bolsonaro-invadiu-quilombo-em-sp/. Acesso em: 04 jan. 2019.

${ }^{10}$ Disponível em: https://www.brasildefato.com.br/2018/12/09/dois-trabalhadores-do-mst-sao-assassinados-emacampamento-na-paraiba/. Acesso em: 14 fev. 2019.

${ }^{11}$ Disponível em: https://brasil.elpais.com/brasil/2018/10/30/politica/1540932003_110027.html?rel=mas. Acesso em: 04 jan. 2019.

${ }^{12}$ Disponível em: https://brasil.elpais.com/brasil/2018/09/26/politica/1537978764_156884.html. Acesso em: 04 jan. 2019.

${ }^{13}$ Disponível em: https://brasil.elpais.com/brasil/2018/08/28/politica/1535410477_538811.html. Acesso em: 04 jan. 2019.
} 
colonização. Entre a décadas de 1980 e 1990, o que se propõe para o campo brasileiro é a fartura de créditos rurais, em uma subsunção da força de trabalho à mundialização capitalista que construía o discurso do business atrelado ao rural. Projeto este que chega à década neoliberal de 1990 intrínseca aos conceitos de eficiência e competitividade, no contexto de abertura do Estado ao mercado, da disseminação do crédito subsidiado e de securitização da dívida rural; bem como, do aumento de conflitos agrários e pressões da classe trabalhadora. Entre os anos de 2003 e 2018, o Brasil se consolida enquanto grande exportador mundial, inserido na comercialização de mercadorias baratas, in natura, produzidas sob condições precarizadas de trabalho; apesar das inúmeras barreiras protecionistas e imposições da Organização Mundial do Comércio (OMC) relacionadas ao desrespeito contra os direitos trabalhistas, recursos naturais e normas sanitárias.

Além disso, a desindustrialização do país se insere como resultado de um novo papel atribuído ao Estado - não mais parceiro de empresas nacionais -, e sim, fomentador de multinacionais imperialistas que controlam setores de energia, alimentos, mineração e exploração vegetal. Tais oligopólios, a exemplo da Coca-Cola, JBS e BRF, estabelecem mandamentos para o campo, tentando acostumar a mentalidade nacional ao agrotóxico, sob o discurso de 'pop' disseminado pela Rede Globo de Televisão; atuam sobre pesquisas científicas, direcionando bolsas e fortalecendo laboratórios em universidades brasileiras, que tentam criar modelos de agricultores e diretrizes de como destituir o debate da questão agrária para uma análise tecnicista, através do ataque contra perspectivas críticas. Desse modo, todo um arcabouço teórico e técnico travestido de 'progresso' visa o barateamento de sementes transgênicas e venenos e o domínio da ciência pelas multinacionais do agronegócio mundial. A (re)primarização da economia brasileira impõe um modelo agroexportador que reordena o território através de políticas públicas elaboradas para perpetuar a ordem capitalista. Portanto, não é ao acaso que Jair Bolsonaro se sinta compelido a negar as questões indígena e quilombola, pois a garantia da demarcação de terras exclui a possibilidade dos grandes latifundiários acumularem renda através da exploração.

Nessa perspectiva de confronto a uma pauta impositiva que inclui venenos, trabalho escravo, negação de direitos trabalhistas e expulsão de povos indígenas e quilombolas, o papel do geógrafo em compreender as contradições no cerne da produção capitalista do espaço se sobressai, no sentido de estar incluso em uma perspectiva de longa duração no movimento de luta contra o capital.

\section{A aula como resistência ao autoritarismo: pensar um campo de luta na sala e para além dela}

Sobre os burgueses e suas atrocidades, Marshall Berman (2007) argumenta que:

Assim como assustam a todos com fantasias a respeito da voracidade e desejo de vingança do proletariado, eles próprios, através de seus inesgotáveis empreendimentos, deslocam massas humanas, bens materiais e dinheiro para cima e para baixo pela 
terra, e corroem e explodem os fundamentos da vida de todos em seu caminho (BERMAN, 2007, p. 124).

Nesse sentido, como prosseguimento do caráter destrutivo burguês, a ofensiva neoliberal almeja o extermínio da teoria crítica para que a contínua exploração do trabalho e da terra seja naturalizada e vista como necessária para a população. Portanto, tudo o que produzir questionamentos sobre a ordem natural das coisas deve ser descartado, pois expor as contradições intrínsecas à realidade significa contrapor a moral e os bons costumes que embasam a aparência da sociedade burguesa e encobrem seu real caráter destrutivo. Desse modo, o presente item propõe argumentar sobre a importância das aulas de Geografia na contraposição ao autoritarismo e a tentativa de destituição do pensamento crítico. Aqui, tem-se como ponto de partida as aulas da disciplina Estrutura Agrária, ofertada no âmbito do Programa de Pós-Graduação em Geografia da Universidade Federal de Sergipe (PPPGEO/UFS), no segundo semestre de $2018^{14}$, na qual conteúdos, debates e o trato com a realidade congregaram-se para a devida negação da fixidez e de toda a reificação imposta pelo mundo da mercadoria.

Em sua "Crítica à Razão Dualista: O Ornitorrinco", Francisco de Oliveira (2008) argumenta, ao contrapor o dualismo cepalino e a ideia de 'crescimento do bolo' da economia para reparti-lo, que o conceito de subdesenvolvimento emerge como oposição do setor atrasado ao moderno; porém, o processo real se constitui a partir de uma unidade de contrários, em que o moderno cresce da existência do atrasado. $\mathrm{O}$ subdesenvolvimento, desse modo, é fruto da expansão da produção capitalista. Ainda segundo o autor, tal noção dualista atenta-se para as questões externas (de conflito entre nações) e desconsidera a oposição entre classes sociais internas. O discurso do subdesenvolvimento contribuiu para a não-elaboração de uma teoria sobre o capitalismo no Brasil, assentando as bases do 'desenvolvimentismo'. Em suas palavras: "a hegemonia de uma classe se afirmou de tal modo que a face já não precisa de máscara" (OLIVEIRA, 2008, p. 34).

Conforme Kosik (1976, p. 23): “a realidade só se muda de modo revolucionário quando termos consciência de que a produzimos. Ou seja, a realidade humano-social como unidade entre produção e produto, sujeito e objeto [...]". Portanto, a construção mútua do conhecimento na sala e para além dela se constitui em exercício contínuo que não se encerra ao fim da disciplina; pelo contrário, a munição teórico-metodológica adquirida ao longo dos dias de aprendizado serão de considerável importância a partir do atual contexto de disseminação do autoritarismo.

\section{Na sala de aula...}

A proposta da disciplina pautou-se na explanação de ideias centrais dos textos propostos, intercalando temas ligados à questão agrária brasileira e aos questionamentos

\footnotetext{
${ }^{14}$ Ministrada em duas partes: a primeira entre os dias 15 e 19 de outubro de 2019, pelo Professor Dr. Marcelo Mendonça (IESA/UFG); e a segunda entre 19 e 23 de novembro, pelo Professor Dr. Adriano Oliveira (IESA/UFG).
} 
de pesquisa de cada mestrando. A partir de Montenegro Gómez (2006) e Favareto (2017) introduziu-se o debate sobre concepções de desenvolvimento para/no campo; o primeiro, tecendo questionamentos sobre o conceito, através de uma perspectiva pósdesenvolvimentista, a qual insere-se na crítica à política de desenvolvimento rural no Brasil de meados dos anos 1990 e a defesa de um projeto alternativo de sociabilidade pautada na defesa da soberania alimentar. De acordo com Montenegro Gómez (2006, p. 20): “[...] o desenvolvimento funcionava como uma estratégia de controle social que reduzia o campo do "possível", daquilo que, segundo os discursos e as práticas do Estado e do capital, era factível". Nesse contexto, a perspectiva do autor é de, através da crítica teórico-metodológica, contrapor o Banco Mundial - que emerge no âmbito de políticas de desenvolvimento rural como o principal organismo multilateral financiador para o agro de governos nacionais e subnacionais -, e toda a noção de 'desenvolvimento possível' que a sociedade capitalista tenta impor.

Favareto (2017), por sua vez, argumenta que o Governo Temer marca o fim de como se pensou desenvolvimento e política pública nos governos do Partido dos Trabalhadores (PT), tendo como marco a extinção do Ministério do Desenvolvimento Agrário (MDA), principal interlocutor da Agricultura Familiar. As discussões em sala de aula apontaram para o emergir de um novo contexto de expansão capitalista no campo brasileiro, através do fortalecimento da bancada ruralista em união às bancadas evangélica e militar (bancadas do boi, da Bíblia e da bala). Contudo, fica evidente que somente em uma leitura que considere a totalidade das relações sociais, se consegue compreender a atualidade dos fatos; pois, a partir da crise mundial de 2007/2008, com a consequente queda nos preços das commodities, o modelo social-desenvolvimentista foi comprometido, fazendo com que os efeitos mais negativos fossem sentidos em meados de 2012. O Brasil iniciou um processo de perda de competitividade e espaço para os países asiáticos, inserindo-se junto aos vizinhos latino-americanos como principais fornecedores de mercadorias in natura. E, como consequência do que alguns autores intitulam reprimarização da economia, os recursos naturais passam a ser objetos de investimentos atrativos através da exploração sem precedentes.

O panorama mundial é caracterizado pela barbárie social, com o aumento da desigualdade para índices mais altos do que os vistos antes das guerras mundiais, a ascensão da microeletrônica e das tecnologias da informação que empregam pouco e produzem poucos bens materiais para o bem-estar, aumento do desemprego e a ascensão de narrativas autoritárias e xenofóbicas. $\mathrm{O}$ contexto brasileiro é marcado por uma brutal inversão de expectativas à década anterior, com uma crise institucional que culminou na articulação de direita e extrema-direita com o apoio da elite, classe média e mídia televisionada contra Dilma Rousseff, produzindo um processo de instabilidade nacional. Desse modo, presencia-se o estancamento do ciclo anterior: aumento da pobreza, diminuição do crescimento econômico e a disseminação de um discurso anticorrupção propício à perda de legitimidade dos governos petistas (FAVARETO, 2017; MITIDIEDO JUNIOR; BARBOSA; SÁ, 2017). 
Os projetos que se apresentaram como possíveis soluções foram dois: o discurso de 'uma só agricultura', através da desarticulação do desenvolvimento agrário e a exclusiva valorização do agronegócio; e a continuidade das políticas sociais, de distribuição de renda e acesso à crédito facilitado pelos camponeses. Portanto, em ambos, não houve a negação da estrutura que sustenta o modo de produção capitalista (relação capital-trabalho); e, desse modo, a crítica ao papel do Estado para a regulação dos mecanismos de exploração do trabalho e da terra em prol da acumulação capitalista. Desde 2003 se construiu a ilusão de uma conciliação entre a agricultura familiar a agronegócio; porém, os interesses díspares logo expuseram as contradições do modelo defendido, culminando no fim do MDA e na tentativa de destituir a posse da terra de povos indígenas, áreas de conservação e comunidades quilombolas. O documentário "À sombra de um delírio verde", por exemplo, espelha as angústias do povo Kaiowá após o aumento do consumo de biocombustíveis durante o Governo Lula, fomentando de um lado, a indústria multimilionária de etanol em fábricas financiadas com capital estrangeiro, mas, de outro, propiciando a invasão da monocultura da cana-de-açúcar, tomando terras indígenas, expulsando-os e forçando-os ao trabalho similar ao escravo, em jornadas extenuantes e condições decadentes de vida.

Ao traçar comentários sobre a luta pela terra após a redemocratização do Brasil, Stédile (2011) informa que a formação do Movimento dos Trabalhadores Sem-Terra se caracterizou por uma rápida espacialização, ganhando força através da presença de grupos da Igreja Católica. Contudo, ao longo dos anos 1990 e, principalmente, após a ascensão da esquerda, criou-se a ilusão de uma pax agrária, em que as políticas públicas estariam neutralizando os conflitos agrários e todos os problemas do/no campo estariam se resolvendo. A própria noção de camponês como sujeito histórico de luta, desde Canudos até as Ligas Camponesas, é abandonada e substituída pela noção de agricultor familiar - conceito elaborado a partir de um decreto, sem um arcabouço teórico que oferecesse sustentação, padronizado para o acesso às políticas públicas. Desse modo, ao contrário de uma alternativa ao modelo de agricultura patronal vigente na estrutura fundiária brasileira desde a colonização, também nos governos de esquerda assistiu-se à desmobilização das lutas, criminalização, repressão e violência de Estado.

A ameaça do fascismo, com acentuados ataques aos povos que garantem a soberania alimentar e a diversidade cultural brasileira exige a autocrítica para que outros caminhos sejam traçados em prol da resistência; contudo, os riscos de perder-se no labirinto de abismos do neoliberalismo são altos, caso não se projete uma alternativa à longo prazo de negação do sociometabolismo do capital, que possui como principal motor o trabalho enquanto valor de troca, precário, informal, temporário e terceirizado. Nas palavras de Dom Tomás Balduíno: "não adianta discurso bonito, é preciso estar perto da terra". 


\section{Para além da sala de aula...}

O aprendizado sobre a Estrutura Agrária brasileira ultrapassou a escala de uma sala de aula e permeou outros espaços para além dos temas/problemas de análise de cada mestrando, a começar pela Feira Agroecológica realizada no próprio Campus Universitário durante as quartas-feiras. Como proposta de instigar a pesquisa sobre formas de resistência, construiu-se uma entrevista informal aos organizadores, residentes do Povoado Colônia Treze, no município de Lagarto, no Centro-Sul Sergipano. A princípio, deparou-se com frutas, verduras e raízes comercializadas sem venenos agrícolas, que atraem docentes, discentes e a população do Bairro Jardim Rosa Elze, nos arredores do Campus, que o adentram em busca de comida saudável (FIGURA 2).

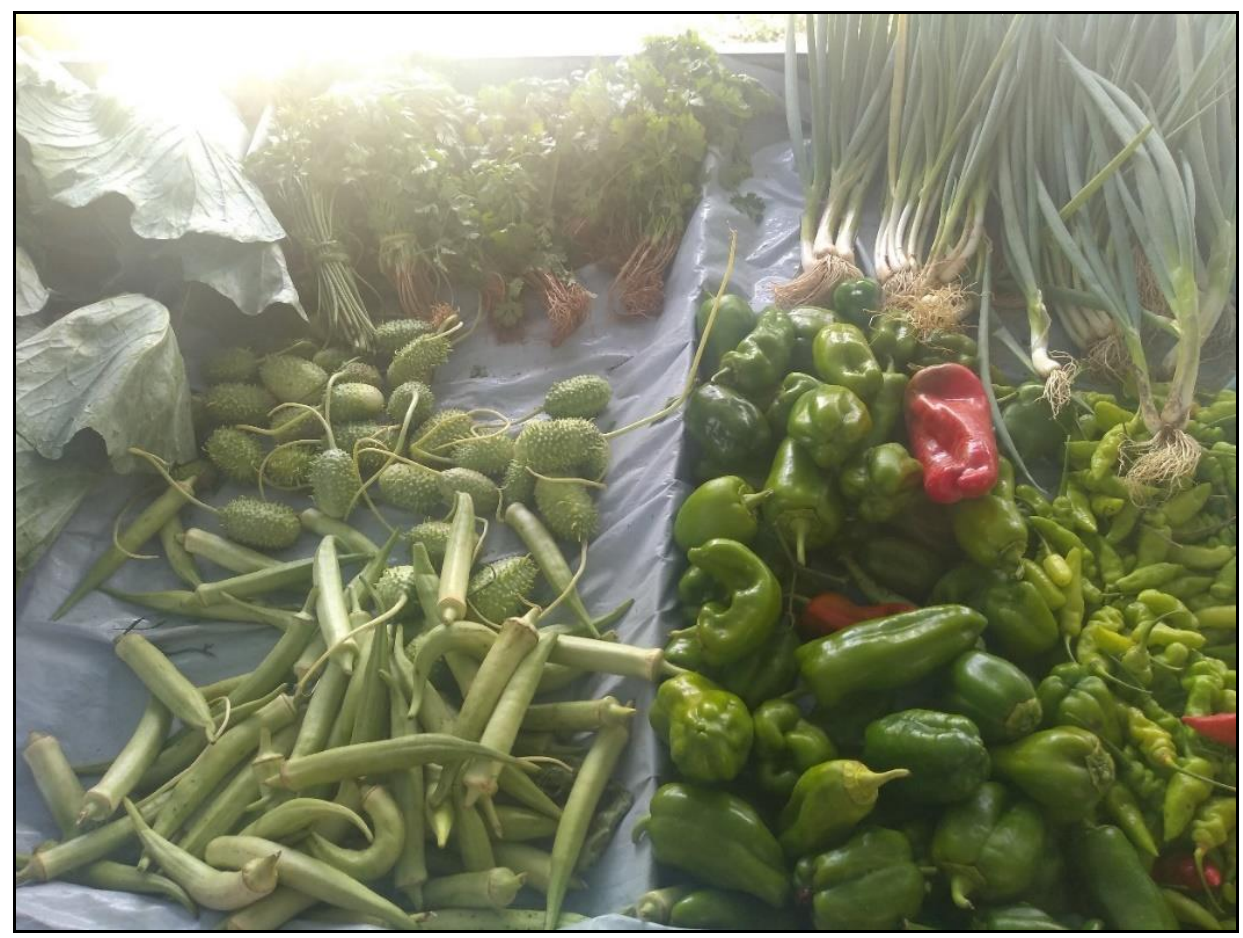

Figura 2: Alimentos comercializados na Feira Agroecológica na Universidade Federal de Sergipe, novembro de 2018

Fonte: Fotografia do autor (2018)

Para que se construa um campo de luta além da sala de aula, é preciso avançar em uma compreensão de Geografia que relacione o ensinado no plano acadêmico ao que se constrói na sociedade em sua contínua práxis. A crítica do discurso geográfico envolve a compreensão de que não se formula uma teoria a partir da simples descrição da realidade imediata, mas através da transformação histórica do real, em uma contínua 
relação entre prática e reflexão (ESCOLAR, 1996). A produção do espaço, nesse sentido, não deve ser apreendida como um fim em si, um resultado final, pois corre-se o risco de se proceder um discurso geográfico incoerente e limitado a categorizações que encerram a análise em si mesma, desembocando em um dogmatismo abstrato. Portanto, quando se propõe trabalhos de campo, rompe-se com a realidade imediata, e abre-se margem para que os sujeitos que a constituem ofereçam e guiem o arcabouço teóricometodológico que compreenda a totalidade das relações humanas em seu movimento contraditório de realização.

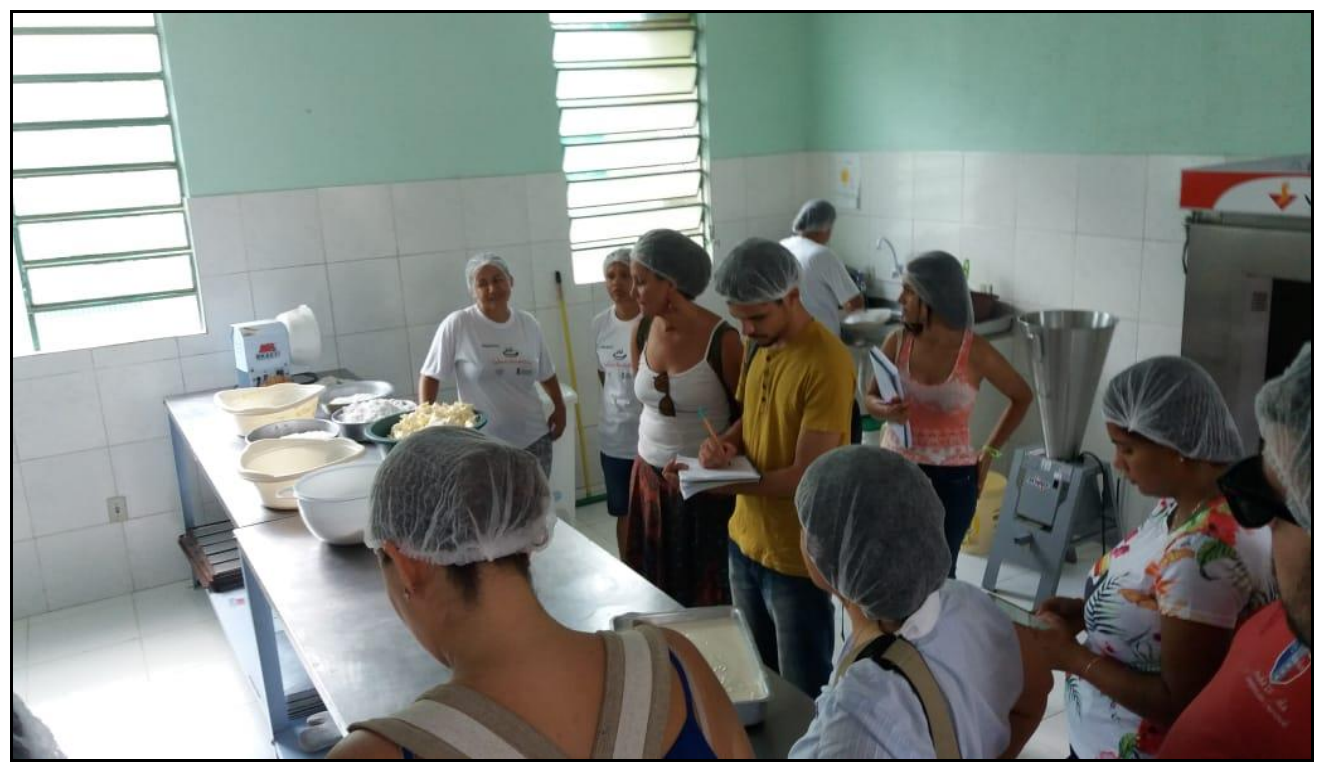

Figura 3: Discentes em visita à Fábrica de Doces, Povoado Tombo, Salgado. SE Fonte: Givaldo Santos de Jesus (2018)

Da feira que adentra o Campus e que também comercializa seus produtos na comunidade da Colônia Treze, a discussão se encaminha para o questionamento sobre quem produz comida para os brasileiros, proposta por Mitidiero Junior; Barbosa; Sá (2017), ao analisar os dados do Censo Agropecuário 2006 e constatar que mais de 70\% dos alimentos que formam a mesa brasileira é produzido pelos camponeses e camponeses, aos quais o Estado nega a terra e o trabalho. Na Fábrica de Doces localizada no Povoado Tombo (FIGURA 3), no município de Salgado, também no Centro-Sul Sergipano, os relatos da camponesa Íris guiam para a constatação de que o desemprego e o subemprego avançam sobre o campo, tão rápidos quanto a implementação de políticas ultraliberais. Desde 2015, quando 46 mulheres trabalhavam na produção dos doces caseiros derivados da mandioca, o número só veio caindo desde então, até chegar ao número atual de 7 mulheres que sustentam o pequeno 
empreendimento fruto do Projeto de Combate à Pobreza Rural Prosperar do Governo do Estado de Sergipe em parceira com o Banco Mundial.

As mulheres relataram que em décadas passadas haviam roças de mandioca e casas onde se produzia farinha; porém, com o crescimento da lavoura de laranja para a fabricação de suco pela Maratá Sucos, cada vez mais, a mandioca perdeu espaço e, após a crise da citricultura a partir de 2010, as camponeses viram-se forçadas a inserirem-se no trabalho informal. Atualmente, a fábrica de doces se reduz à produção para os festejos juninos, sendo que o trabalho na fábrica não consegue oferecer uma renda básica para as trabalhadoras, que possuem outras ocupações, o que se leva a questionar um dos conceitos mais disseminados nos últimos anos: empoderamento. Em que sentido o modo de produção capitalista oferece poder para camponesas dissociadas da terra em um processo histórico de avanço do capital enquanto relação social, que no contexto de crise estrutural, se tornam força humana sobrante entregue à multifuncionalidade? De certo, a visibilidade e o apoio ao trabalho na fábrica desempenhado exclusivamente por mulheres é um avanço contra o patriarcalismo que impõe uma divisão sexual do trabalho; porém, o trato com a realidade também se configura de cuidados teórico-metodológicos para não se deslocar a análise de seu arsenal contra o sociometabolismo que sustenta a barbárie social e a perdura a níveis cada vez maiores no desenvolvimento desigual e combinado do modo de produção capitalista. A polêmica suscita o debate e não se encerra neste artigo, encontrando eco em possíveis campos para a produção do conhecimento contínuo.

Se o debate sucumbir à harmonia cega como forma de negação do pensamento crítico, nada mais precisa ser contestado, pois tudo se encontra em ordem e progresso; afinal, a pátria está acima de tudo e Deus acima de todos: a principal desordem - o marxismo - está vencido e sem forças para contrapor a 'beleza' do capitalismo. Portanto, sem o pensamento crítico, não se poderá contestar a situação de mais de 1,4 bilhão de seres humanos em situação de trabalho vulnerável, de acordo com os dados da Organização Internacional do Trabalho $(\mathrm{OIT})^{15}$.

Da discussão sobre trabalho (e a sua precarização) chega-se à casa de farinha do Senhor Pedro (FIGURA 4), no espaço agrário do município de Lagarto, que juntamente com as raspadoras de mandioca e as 'tiradoras' de tapioca sobrevivem a partir da renda camponesa. Durante três dias a rotina se repete: descarrega-se a mandioca comprada de roças distantes, raspa-se as toneladas desde madrugada até o final da tarde, tritura-se as mandiocas raspadas para a produção da massa (que serve para a retirada da tapioca), que, posteriormente, é prensada (dando origem à manipueira que alimenta o gado), triturada novamente, cozida e peneirada.

\footnotetext{
${ }^{15}$ https://nacoesunidas.org/oit-desemprego-e-deficits-de-trabalho-decente-continuarao-altos-em-2018/
} 


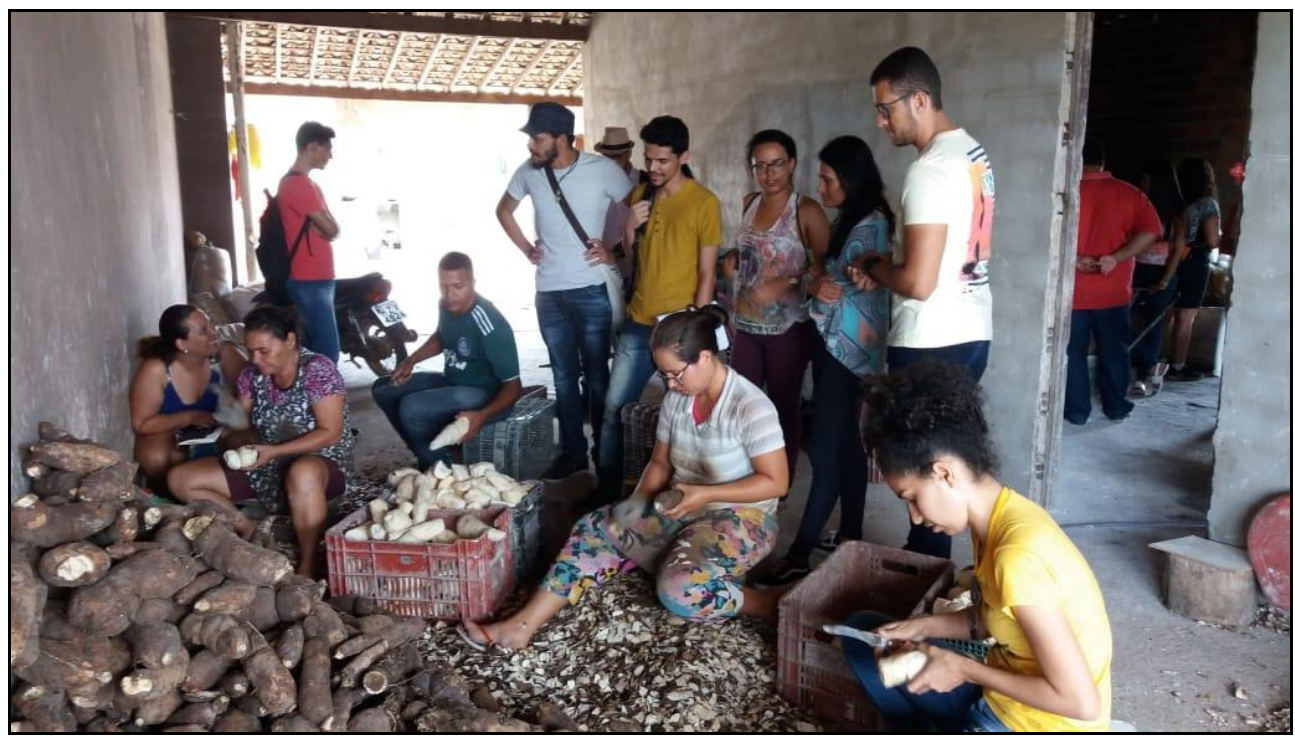

Figura 4: Discentes em visita à casa de farinha, Lagarto. SE Fonte: Givaldo Santos de Jesus (2018)

Os dias de farinhada acompanham gerações de camponeses sergipanos, que comercializam o produto final nos mercados municipais de Itabaiana e Aracaju, os dois principais centros de abastecimento do estado, além de consumirem a farinha e a tapioca e aproveitarem a casca da mandioca para alimentar o gado. A mecanização do processo produtivo não excluiu o trabalho humano das distintas atividades dentro da casa de farinha, e, mesmo que a sujeição da renda camponesa ao capital exista de modo indireto, com o uso intensivo de venenos para 'limpar' as malhadas de mandioca e a determinação do preço do saco de farinha de acordo com a oferta/demanda, trabalho camponês como fonte de manutenção da unidade familiar continua presente. Contudo, a casa da farinha e seus sujeitos não devem ser deslocados do contexto neoliberal, pois no circuito do processo de acumulação e reprodução ampliada do capital, eles necessitam ser produtores individualizados, mesmo que o sentido de coletividade esteja mantido. $\mathrm{O}$ sociometabolismo do capital sobrevive na destruição do humano e no constante processo de individualidade, e, desse modo, a construção de um campo de luta deve considerar a destruição das categorias que sustentam o modo de produção: o capital como relação social, o trabalho em seu sentido abstrato e o Estado como regulador da acumulação capitalista.

Quando a Senhora Josefa, em sua luta por melhores condições de vida na comunidade quilombola de Sítio Alto, no município de Simão Dias, no Sul Sergipano (FIGURA 5), se utiliza do aparato jurídico do Estado na concretização de seus objetivos, não o faz por este ser benévolo, mas por uma demanda advinda da negação histórica ao acesso à terra e ao trabalho para a população negra brasileira. 


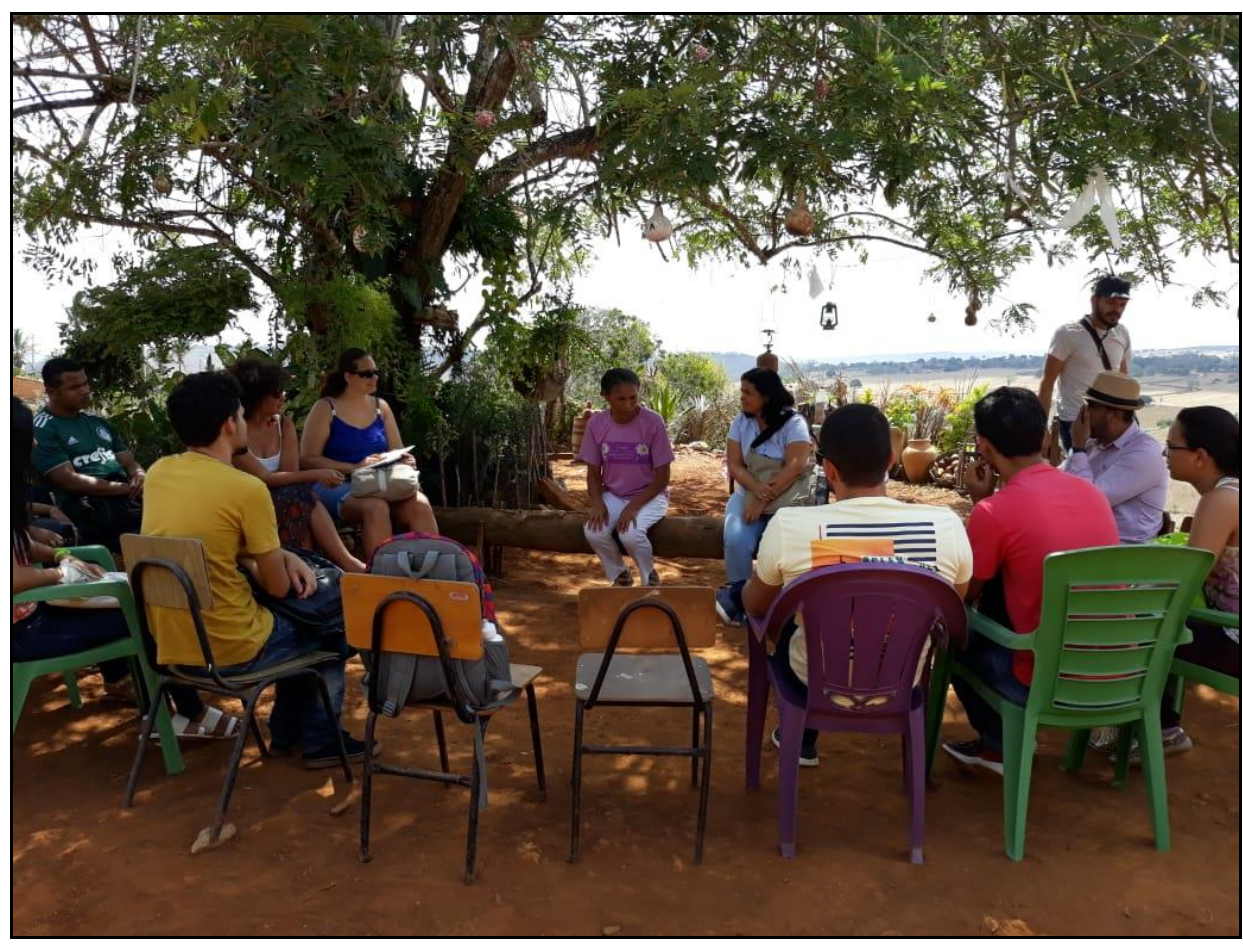

Figura 5: Discentes reunidos na comunidade quilombola Sítio Alto, Simão Dias. SE Fonte: Luciana Priscila do Carmo (2018)

A fala de Josefa guiou o olhar dos geógrafos no tempo-espaço de constituição da comunidade e transformação das condições sociais, com o passado marcado pela fome e sede, com casas de taipa, poucas vestimentas e cobertores feitos de gibão. Uma miséria que contrastava com as demais povoações e que se explicava a partir de discursos sobre ser aquele lugar 'amaldiçoado'. A barbárie social instigou a ação coletiva da população local, através de mutirões para a construção de casas e a participação nas reuniões do Sindicato dos Trabalhadores Rurais do município; posteriormente, com a criação da Associação dos Moradores do Povoado Caraíbas e as constantes demandas da comunidade expostas durante as reuniões geraram incômodo e episódios de racismo passaram a ser frequentes.

A pressão do próprio Estado pelo fechamento da casa de farinha comunitária, devido ao fato dos moradores da comunidade alegarem residir no Povoado Caraíbas, como forma de ocultar o passado quilombola, forçou a criação de uma Associação própria e a afirmação de que a luta pelo reconhecimento se daria através do engajamento de toda a população do Sítio Alto. A construção de uma capela e a instalação das primeiras 30 cisternas com a ação de técnicos da Articulação Semiárido Brasileiro (ASA) se constituíram nos primeiros avanços na luta por uma vida digna para os 
moradores. Atualmente, as plantações de feijão, milho, mandioca, frutas, verduras e ervas medicinais no alto da comunidade contrastam com o avanço da monocultura de milho transgênico na paisagem ao redor, o que nos faz questionar sobre o verdadeiro papel do Estado na manutenção das relações de exploração e dominação dos proprietários dos meios de produção sobre os camponeses.

Portanto, concorda-se com a análise de Escolar (1996), quando este afirma que é preciso esclarecer que:

A geografia não é 'uma arma que serve para a guerra', nem instrumento para revelar 'máscaras sociais'; pelo menos não mais que qualquer outro saber sobre a realidade social. Com base nessa posição, não é a Geografia que deve ser qualificada de uma ou outra maneira, mas os sujeitos comprometidos que dela fazem uso em determinadas situações concretas (ESCOLAR, 1996, p. 37).

\section{Considerações finais: para que o caminhar não cesse}

As palavras finais desse escrito não cessam o caminho de transformação da realidade; pelo contrário, reverbera a necessidade de efetiva negação daquilo que nega a condição humana. Os versos do Cordel de Zé de Quinô, um alagoano escritor e trabalhador informal, atualmente mestrando do Programa de Pós-Graduação em História da Universidade Federal de Sergipe, ecoam a necessidade da luta para os largos, praças, ruas, avenidas, becos, estradas de terra, florestas, sertões, agrestes e subterrâneos:

No contexto atual; em nossa sociedade; o trabalhador do campo; e também o da cidade; vive uma situação; de total exploração; tremenda calamidade. Muito vai acontecer; nesse mundo do trabalho; 'tá' mais parecendo um jogo; de dominó ou baralho; pois o novo presidente; para o azar de nossa gente; veio para descer o malho (QUINÔ, 2018, p. 1).

Portanto, é preciso enfatizar a importância da compreensão crítica sobre o real, em suas noções de movimento contraditório do espaço/tempo e de transformação constante das coisas, como Marx havia compreendido no século XIX ao teorizar sobre as distintas fases do capital no processo de acumulação. Conforme Terry Eagleton nos ensina: Marx estava certo, e nesse momento, se não existem fábricas e chaminés com massas proletárias em situação insalubre, não se deve negar a existência da barbárie, pois as multidões famintas e expropriadas nas favelas das grandes megalópoles, nos campos envenenados e nas florestas e rios ameaçados são provas da destrutibilidade causada pelo atual modo de produção.

“O caminho aberto leva à praça pública” (BERMAN, 2007, p. 20); nesse sentido, é preciso fazer dos espaços abertos um lócus de perpetuação do pensamento crítico, da Geografia e da noção de espaço para além de simples área - seja oferecendo café e bolo em troca de um debate sobre as notícias manipuladas diariamente nos jornais 
televisionados e nas Fake News do WhatsApp, distribuindo livros e cartilhas, reunindo-se com amigos, professores, alunos e familiares para debater sobre o que pensam dos cortes, do ataque ao campo e ao trabalho. A célebre frase "trabalhadores de todo o mundo, uni-vos" cada vez mais encontra eco ao longo do tempo, não devendo ser considerada como fixa ao século XIX. Em um planeta em que bilhões perecem em fome, desemprego, informalidade e furto de recursos naturais para que poucos possam se amontoar em lucro e riqueza é preciso se valer da crítica marxista enquanto método que interpreta a realidade em seu movimento histórico, desigual e combinado, fornecendo à ciência geográfica seu potencial transformador.

\section{Referências}

BERMAN, M. Tudo que é sólido desmancha no ar: a aventura da modernidade. São Paulo: Companhia das Letras, 2007.

BRADBURY, R. Fahrenheit 451: a temperatura na qual o papel fogo e queima do livro pega fogo e queima. São Paulo: Globo, 2012.

EAGLETON, T. Marx Estava Certo. Rio de Janeiro: Nova Fronteira, 2012.

ESCOLAR, M. Crítica do Discurso Geográfico. São Paulo: Hucitec, 1996. p. 9-47.

FAGUNDES, R. S. O homem lata: como a educação transforma gente em capital humano. Revista Le Monde Diplomatique Brasil (online). Disponível em: https://diplomatique.org.br/como-educacao-transforma-gente-em-capital/. Acesso em: 02 jan. 2019.

FAVARETO, A. Concepções de desenvolvimento e de intervenção pública no Brasil rural sob o governo Temer e além. Revista Raízes, v. 37, n. 2, jul-dez/2017.

HOBSBAWM, E. A Era das Revoluções: 1789-1848. São Paulo: Paz e Terra, 2010.

KOSIK, K. Dialética do Concreto. Rio de Janeiro: Paz e Terra, 1976.

MITIDIERO JUNIOR, M. A.; BARBOSA, H. J. N.; HÉRICK DE SÁ, T. Quem produz comida para os brasileiros? 10 anos do Censo Agropecuário 2006. Revista Pegada. vol. 18 n.3 set/dez, p. 7-77, 2017.

MONTENEGRO GOMÉZ, J. R. Desenvolvimento em (des) construção: narrativas escalares sobre desenvolvimento territorial rural. 2006. $439 \mathrm{f}$. Tese (Doutorado em Geografia) UNESP/FCT, Presidente Prudente, 2006.

MARX, K. Manifesto do Partido Comunista. Porto Alegre: L\&PM, 2007.

MARX, K. O Capital: crítica da economia política. São Paulo: Boitempo, 2017.

OLIVEIRA, F. de. Crítica à Razão Dualista: O Ornitorrinco. São Paulo: Boitempo, 2008. 
QUINÔ, Z. de. A Exploração no Comércio de Arapiraca. Literatura de Cordel, 2018, $2^{\mathrm{a}}$ edição. 8p.

STÉDILE, J. P.; ESTEVAM D. A questão agrária no Brasil: o debate tradicional. 2 ed. São Paulo: Expressão Popular, 2011. p. 15-31.

\section{Bruno Andrade Ribeiro}

Bolsista de Mestrado do Conselho Nacional de Desenvolvimento Científico e Tecnológico (CNPq) do Programa de Pós-Graduação em Geografia da Universidade Federal de Sergipe (PPGEO/UFS), orientado pela Professora Dra. Josefa de Lisboa Santos. Membro do Grupo de Pesquisa Relação Sociedade Natureza e Produção do Espaço (PROGEO) e do Laboratório de Estudos Territoriais (LATER).

Avenida Marechal Rondon, S/N, Jardim Rosa Elze, Cidade Universitária Professor José Aloísio dos Campos, Programa de Pós-Graduação em Geografia (PPGEO), Didática II, $2^{\circ}$ andar, Sala do Laboratório de Estudos Territoriais (LATER), São Cristóvão, Sergipe, CEP: 49100000

E-mail: ribeiro.pensador@gmail.com

\section{Josefa de Lisboa Santos}

Professora Associada do Departamento de Geografia (DGEI) do Campus de Itabaiana e do Programa de Pós-Graduação em Geografia (PPGEO) da Universidade Federal de Sergipe (UFS). Líder do Grupo de Pesquisa Relação Sociedade Natureza e Produção do Espaço (PROGEO/DGEI/PPGEO/UFS) e do Laboratório de Estudos Territoriais (LATER/PPGEO/UFS); Pesquisadora na área de Geografia Agrária e Análise Regional.

Avenida Marechal Rondon, S/N, Jardim Rosa Elze, Cidade Universitária Professor José Aloísio dos Campos, Programa de Pós-Graduação em Geografia (PPGEO), Didática II, $2^{\circ}$ andar, Sala do Laboratório de Estudos Territoriais (LATER), São Cristóvão, Sergipe, CEP: 49100000.

E-mail: josefalisufs@gmail.com 